\title{
Growth and survival of marine sponges, Stylissa massa (Carter, 1887) and Liosina paradoxa (Thiele, 1899) in sea and land based culture systems
}

\author{
R. KIRUBA SANKAR, N. K. CHADHA*, S. DAM ROY, PARAMITA BANERJEE*, NEELAM \\ SAHARAN*AND P. KRISHNAN \\ ICAR-Central Island Agricultural Research Institute, Port Blair - 744 101, Andaman and Nicobar Islands, India \\ ${ }^{*}$ Central Institute of Fisheries Education, Mumbai - 400 061, Maharashtra, India \\ e-mail: rkirubasankar@gmail.com
}

\begin{abstract}
Two species of marine sponges Stylissa massa and Liosina paradoxa were cultured in cages (in situ) and in land based aquaria (ex situ) over a period of 120 days. Growth and survival were evaluated using four substrates viz., tile, block, coral rock and rope) under both in situ and ex situ conditions. L. paradoxa in cages recorded significant increase $(\mathrm{p}<0.05)$ on day 90 i.e., by $70 \%$ compared to initial volume whereas at 120 days there was a significant $(\mathrm{p}<0.05)$ decrease $(54.22 \%)$. S. massa showed significant increase $(\mathrm{p}<0.05)$ in growth by $95.6 \%$ at 120 days compared to initial volume. Negative growth was recorded in $S$. massa under aquarium conditions while $L$. paradoxa recorded good growth as well as survival and performed exceptionally well in aquarium during the entire experimental period of 120 days. In cages, $90.62 \%$ survival was recorded for S. massa in 120 days. Among the different substrates used, coral rocks gave $100 \%$ survival whereas other substrates such as tiles, blocks and ropes showed $87.5 \%$ survival. Under aquarium conditions, S. massa showed overall survival of $81.25 \%$ and among the different substrates, $100 \%$ survival was obtained with coral rocks, $87.5 \%$ with blocks, $75 \%$ with ropes and the lowest survival of $62.5 \%$ was recorded with tiles.
\end{abstract}

Keywords: Aquarium, Cage, Growth, Mariculture, Metabolite, Sponges, Survival

\section{Introduction}

Sponges are known for presence of rich variety of bioactive metabolites (Sipkema et al., 2005). Since 1950 s, interest in sponges increased due to the discovery of bioactive secondary metabolites (Bergmann and Feeney, 1950). The importance of marine sponges and its application to mankind has been gaining importance globally. More than 5300 different products are recorded from sponges and their associated microorganisms and every year around 200 new metabolites are reported (Lipton and Shine, 2009). Owing to their high potential and demand, there are chances of overexploitation of the natural stocks. Since the discovery of pharmacologically interesting compounds in sponges many attempts have been made to culture sponges as renewable sources of these metabolites. In order to obtain sufficient amounts of bioactive compounds, a sustainable production technique is required. Sponge aquaculture is one possible method of supplying sufficient and sustainable quantities of sponge metabolites that have pharmaceutical potential (Osinga et al., 1999). The ability of sponges to reproduce from small fragments/explants make them attractive for commercial farming (Colin and Arneson, 1995; Macmillan, 2002). The first scientific report on methods for cultivating sponges were published in the late $19^{\text {th }}$ and early $20^{\text {th }}$ centuries (Smith, 1897; Cotte, 1908). These early studies generally concentrated on in situ cultivation experiments with species of the family Spongiidae, which were and still are of commercial importance as bath sponges. Many species of sponges were found to be slow growing organisms (Dayton, 1979; Ayling, 1983; Garrabou and Zabala, 2001). In order to get requisite quantity of sponges without affecting the natural population, mariculture is the best available option which may be either sea based or land based.

Andaman Islands are bestowed with rich marine resources among which sponges are one of the most widely distributed resource. The present study evaluated the growth and survival of two sponge species viz., Stylissa massa (Carter, 1887) and Liosina paradoxa Thiele, 1899 in the sea in fabricated cages as well as in aquarium tanks, in the Andaman Islands. Eight alkaloids having anti-tumour potential were derived from S. massa (Tasdemir et al., 2002). Several compounds like hymenialdisine, an alkaloid with potential against human neurodegenerative diseases were found from S. massa. L. paradoxa contains sterols and its main steroidal constituents were found to be Delta ${ }^{5}$ sterols and 
$5 \alpha, 8 \alpha$ epidoxy sterols. (Aknin et al., 2010). In the present study four different substrates viz., tiles, block, coral rock and ropes were evaluated for culture of S. massa and $L$. paradoxa in cages as well as in aquaria for a period of 120 days.

\section{Materials and methods}

The in situ culture experiments in cages were conducted in the Andaman Islands, near the Marine Hill shore, Port Blair, South Andaman (11 ${ }^{\circ} 40^{\prime} 38.77^{\prime \prime}$; $\left.92^{\circ} 44^{\prime} 20.11^{\prime \prime} \mathrm{E}\right)$ at $3-5 \mathrm{~m}$ depth on a rocky bottom. Ex situ culture in aquaria was conducted at the marine research laboratory of ICAR-Central Island Agriculture Research Institute, Port Blair. Sponges were collected by SCUBA diving from North Bay and transported to the laboratory. As sponges require substrates for attachment, growth and survival, sponge explants were cut underwater using sterile knife and were pierced with nylon threads from side to side and tied on to the substrates viz., tile, concrete blocks, coral rocks (natural substrate) and ropes. The cages (1x1x0.5 m) were fabricated with four compartments in order to accommodate the four substrates. The substrates were tied to the cages to avoid toppling or dislodgement. Cages were placed at depth of 3-5 $\mathrm{m}$ and tied on to the rocks to avoid disturbances due to waves. The cages were then overlaid with a polythene coated steel mesh of $1.5 \mathrm{~cm}$ mesh size, to prevent any possible predation. In total, 16 cages ( 8 cages per species) were used for the experiment (Fig. 1a). For ex situ cultivation experiment, 16 aquarium tanks (8 tanks per species) filled with unfiltered seawater without any additional nutrients were used. Sponge explants prepared were tied to the four different substrates (tile, concrete blocks, coral rocks and ropes) and placed in the tanks (Fig. 1b-c).

Growth was measured once in 15 days, as increase in the surface volume estimated from length, breadth and height of explants and expressed in $\mathrm{cm}^{3}$ following Schifenhovel and Kunzmann (2012). Initiation of attachment and survival of both the species were noted during the first fortnight. When mortality was observed, dead explants were removed at first notice to avoid damage to other sponge explants. Survival rate of sponges were calculated using the formula (Schifenhovel and Kunzmann, 2012) as:

Survival, $\mathrm{S} \%=\mathrm{N}_{\mathrm{T}} / \mathrm{N}_{0} \times 100$

where, $\mathrm{N}_{0}$ - number of sponges at start of the experiment and $\mathrm{N}_{\mathrm{T}}$ - number of sponges on the day of sampling

Data analysis was carried out using one way ANOVA with SPSS version16.0.

\section{Results and discussion}

\section{In situ cultivation in sea cages}

Water quality parameters recorded in the cages were: $\mathrm{pH}-7.9$ to 8.2 , temperature -26 to $28^{\circ} \mathrm{C}$, salinity -33.5 to $35 \%$ and dissolved oxygen -5 to $5.3 \mathrm{mg} \mathrm{l}^{-1}$. Growth of $L$. paradoxa explants varied significantly $(\mathrm{p}<0.05)$ between the sampling days. On an average, L. paradoxa explants grew from initial size of $6.27 \mathrm{~cm}^{3}$ to $9.67 \mathrm{~cm}^{3}$ on termination of the experiment. Positive growth rate was recorded during the first 90 days $(p<0.05)$ of the culture period followed by a decrease in volume. Explant volume increased by $72 \%$ on $90^{\text {th }}$ day $\left(10.67 \pm 0.31 \mathrm{~cm}^{3}\right)$ while significant growth reduction $(p<0.05)$ was recorded on $105^{\text {th }}$ and $120^{\text {th }}$ day of sampling (Fig 2a). Among the four substrates used for cultivation of sponges in cages, coral rock gave significantly $(\mathrm{p}<0.01)$ better growth compared to other substrates and there was no significant difference between other three substrates. Growth of explants was lowest in the block substrate (Fig 2b). In case of $L$. paradoxa culture in cages, out of 32 explants 27 explants survived with overall survival rate of $84.37 \%$.

S. massa in cages showed increasing growth trend throughout the experimental period, with highest growth recorded on 120 days of rearing $\left(14.30 \pm 2.04 \mathrm{~cm}^{3}\right)$. However, on day 105 of rearing a reduction in growth was observed $\left(13.34 \pm 1.83 \mathrm{~cm}^{3}\right)$ (Fig. 2c). Performance of $S$. massa on all the substrates was good but coral rock substrate $\left(12.05 \pm 0.18 \mathrm{~cm}^{3}\right)$ showed the highest $(\mathrm{p}<0.05)$ followed by concrete block $\left(11.84 \pm 0.19 \mathrm{~cm}^{3}\right)$, tile $\left(10.85 \pm 0.19 \mathrm{~cm}^{3}\right)$ and rope $\left(10.95 \pm 0.19 \mathrm{~cm}^{3}\right)$ (Fig. 2d).

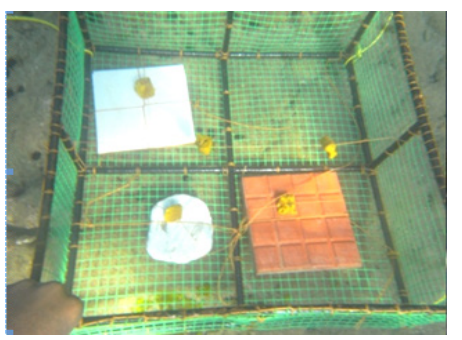

(a)

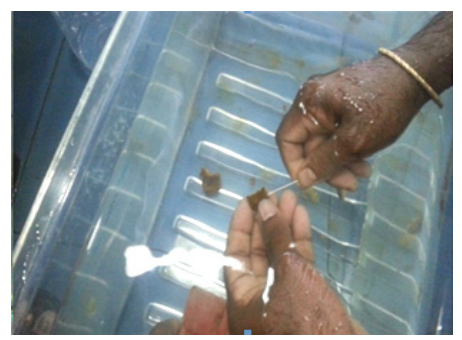

(b)

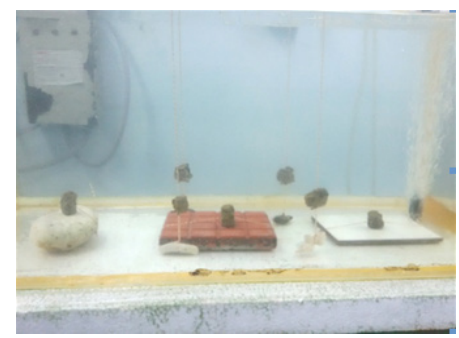

(c)

Fig. 1. a. Sponge explants in cages; b - c: Sponge explants in aquaria 


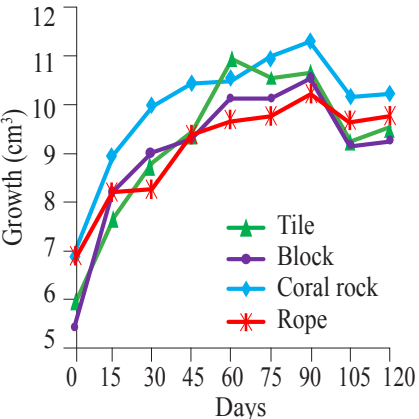

(a)

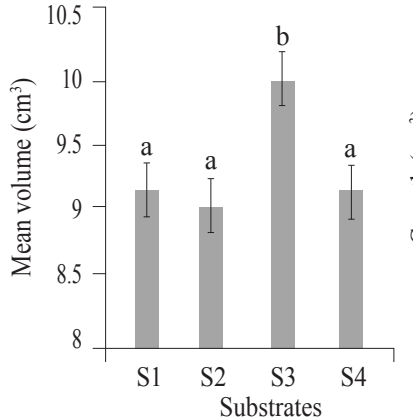

(b)

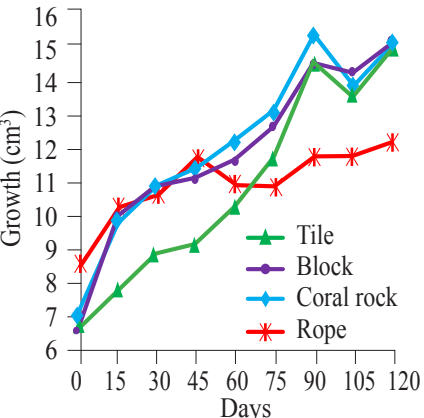

(c)

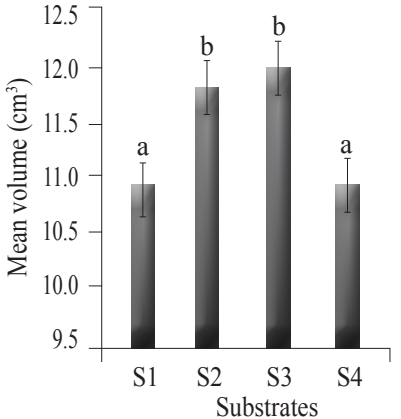

(d)

Fig. 2. Growth of Liosina paradoxa (a-b) and Stylissa massa (c-d) on different substrates in cages

Out of the 32 explants of $S$. massa, 29 explants survived at 120 days showing $90.62 \%$ survival. Among the different substrates, coral rocks showed $100 \%$ survival rate whereas other substrates (tile, block and ropes) showed only $87.5 \%$ survival.

For sponge culture to be commercially viable explants should attain at least double the size each year (Crawshay, 1939) and should have survival greater than 90\% (Verdanel and Vacelet, 1990). In cages, S. massa with mean initial volume of $7.31 \mathrm{~cm}^{3}$ attained $14.30 \mathrm{~cm}^{3}$ on termination of the experiment. L. paradoxa in cages recorded maximum increase in volume at day 90 by $70 \%$ compared to initial volume whereas at 120 days it decreased to $54.22 \%$. S. massa showed $95.6 \%$ increase in volume at 120 days compared to initial volume with no shrinkage in growth. Culture environment could be a major discriminating factor for growth and survival in sponges. Our cage site was prone to high water flow and sediments, where in many a time sponges were covered by silt and deposits which were cleaned prior to measurements. If sediments affect the inflow of water in sponges it might probably lead to occasional shrinkage since they are filter feeders. Marine sponge Callyspongia subargimera grew in open sea conditions at $99.94 \mathrm{mg}$ day $^{-1}$ in Kerala, India (Lipton and Shine, 2009). Our study had limitation with reference to growth measurement as we measured increase in volume using length, breadth and height. Most advanced methodologies like 3D-photogrammatry techniques are not much used in Indian context.

Survival rate of sponges is an important aspect which indicates the potential of sponges for mariculture. Survival rate mainly depends on environmental conditions, initial damage during explant preparation and type as well as availability of substrates. Survival of $S$. massa with coral rock substrates was $100 \%$. In cages, mean volume of $S$. massa and L. paradoxa were higher in coral rock substrates compared to the other substrates. Observations made by Decaralt et al. (2010) when studying in situ culture of Dysidea avara in North-west Mediterranean comparing growth in cage, glue and rope methods, indicated that cage method was best for survival, glue method being best for growth and rope method for bioactivity. From Indonesia (close to Andamans in geographical location), high survival rates of $80 \%$ for the sponge Amphimedon paravirdis, and 92\% for Ircinia ramose were reported (Devoogd, 2005). In our study, mortality occurred during first 15 days and hardly any mortality was noticed further as mostly sponges were acclimatised. Similar observations showed that morality mostly occurs in the initial days of transplantation (Pronzato et al., 1999; van Treeck, 2003) and hence survival rates will give good impression on the sensitivity of the species (Devoogd, 2005).

Sediment load in cages is also one of the important issue which might have influenced the survival and growth of sponges. Bakus (1967) in experiments conducted at Fanning Island, Central Pacific indicated that many sponges and ascidians are adversely affected by sediment deposition by burial and clogging of canals and chambers. During the present study, sponges were mostly covered with sediments which were cleaned every time prior to morphometric measurements. Cages were cleaned regularly to remove possible sediment accumulation at the site. Though survival was not high, i.e., above $90 \%$ as described by Verdenal and Vacelet (1990), survival might improve if initial damage is minimal. Site selection of cages is also important factor for growth and survival. Our site was chosen in close proximity for easy monitoring and maintenance and it's not a protected bay. UV radiation in the sunlight is also believed to limit the growth of sponges (Duckworth et al., 1997). As the cages were placed at shallow waters in depth $<5 \mathrm{~m}$, sunlight also could have influenced the growth of sponges.

\section{Ex situ cultivation}

Under aquarium culture, negative growth was recorded in $S$. massa after 15 days of culture (Fig. 3a). 


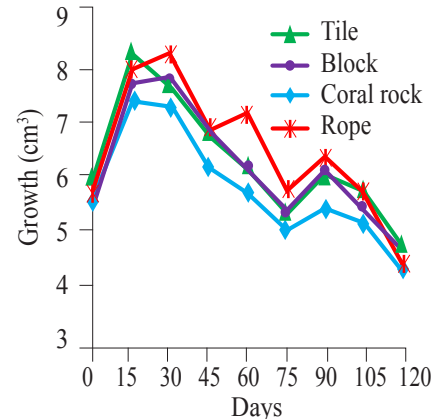

(a)

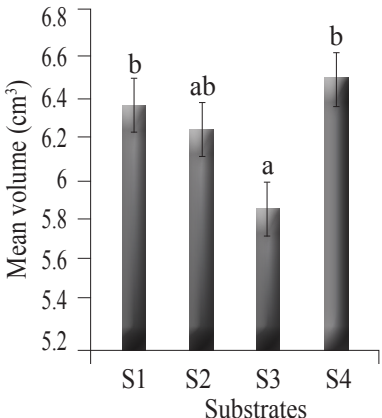

(b)

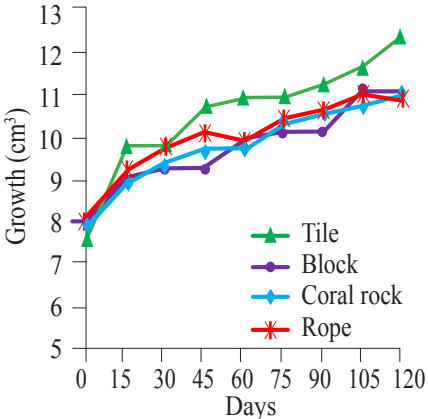

(c)

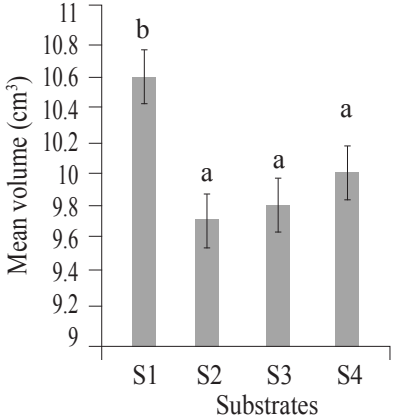

(d)

Fig. 3. Growth of Stylissa massa (a-b) and Liosina paradoxa (c-d) in different substrates in aquarium

Mean volume of $S$. massa in aquarium on day 15 $\left(7.76 \pm 1.10 \mathrm{~cm}^{3}\right)$ and day $30\left(7.70 \pm 1.24 \mathrm{~cm}^{3}\right)$ was at par and significantly higher than that of other days. After $30^{\text {th }}$ day, reduced growth was observed till the end of the culture period. Lowest volume was observed on day $120\left(4.61 \pm 0.76 \mathrm{~cm}^{3}\right)$. The volume decreased significantly $\left(4.61 \pm 0.76 \mathrm{~cm}^{3}\right)$ by $25 \%$ compared to the initial volume of $5.77 \pm 0.56 \mathrm{~cm}^{3}$. Significantly higher growth $\left(6.497 \pm 130 \mathrm{~cm}^{3}\right)$ was recorded with rope and tile substrates as compared to that of coral rock (Fig. 3b). Out of the 32 explants of $S$. massa used at the start of the experiment, only 26 explants survived at the end of the experiment with an overall survival of $81.25 \%$. Survival however varied among the substrates with $100 \%$ survival for coral rock. Coral rock, a naturally available substrate, showed good survival and attachment. Survival was also dependent on attachment. Sponge explants did not attach well on tiles and therefore, lowest survival $(62 \%)$ was observed with tiles. In case of Liosina paradoxa highest mean growth of $11.33 \pm 0.21 \mathrm{~cm}^{3}$ (44\% increase in volume), was recorded during 120 days of culture. The trend of growth in four substrates is shown in Fig 3c. Among the four substrates (tile, block, coral rock and rope), explants cultured on tiles showed significantly higher growth $\left(10.58 \pm 0.15 \mathrm{~cm}^{3}\right)$ than that of the other three substrates (Fig. 3c). There was no significant difference among other three substrates during 120 days of culture of $L$. paradoxa (Fig. $3 \mathrm{~d}$ ). Out of the 32 explants of L. paradoxa, 30 explants survived at the end of the experiment showing highest survival of $93.75 \%$ with block and coral rock showing 100\% survival. Sponges in tile and rope substrates showed only $87.5 \%$ survival as the explants failed to attach on the substrates initially leading to mortality.

In India reports on land based culture of sponges are reported by Lipton and Shine (2009) for culturing Echinodictyum gorgonoides in aquarium tanks using recirculated seawater. There is no previous report on ex situ cultivation of sponges in India. In another study, three specimens of the marine sponge Spirastrella inconstans cultured in captivity in 2 t FRP tanks showed height increments of 26,12 and $11 \mathrm{~mm}$ in one month (Vinod et al., 2009). Studies on growth of L. paradoxa has not been reported elsewhere whereas Schifenhovel and Kunzmann (2012) have reported on culture of $S$. massa in Indonesia. Interestingly $L$. paradoxa performed well in aquarium compared to $S$. massa which exhibited a negative growth. The growth patterns were likely to be the result of several factors like food limitation and behavioural responses in explants (Duckworth, 2009). Water exchange was done every day or on alternate days in order to maintain aquarium conditions suitable for the optimum growth and survival of sponges. Aquarium cultivation using running, unfiltered seawater seemed to be the most successful system with respect to long term in vitro cultivation of marine sponges (Osinga et al., 1999). It was assumed that the natural seawater would be good enough to provide nutrients required for the growth of sponges and no supplementation was done during the present study. The dead sponges were immediately removed from the aquaria as they could easily pollute the water which might influence the growth and survival of other sponges. Survival rates were critical as explained by Verdenal and Vacelet (1990), as a minimum survival of $90 \%$ was essential for mariculture. High survival of $93.75 \%$ was recorded for L. paradoxa in aquarium, while for $S$. massa, $81 \%$ survival was recorded in aquarium. In India, Lipton and Shine (2009) reported that E. gorgonoides survived for 80 days in aquarium culture of sponges.

Ex situ approaches of marine sponge cultivation have shown encouraging growth rates (Osinga et al., 1999; 2001; 2003). Several attempts have been made to culture sponges on land. Several works have been conducted for studying growth of sponges like Cliona celata using unfiltered seawater (Waburton, 1958), Ephydatia fluviatilis using E. coli (Porrier et al., 1981), Halichondria panacea using unfiltered seawater (Barthel and Theede, 1986), Microciona prolifera fed on Dunaliella euchlora (Simpson, 1968) and Ophlitaspongia seriata fed with Isochrysis galbana (Fry, 1971) as reviewed by Osinga et al. (1999). Studies using alternate feedings with unfiltered 
seawater could give more idea on the comparative growth and influence of feed on growth and survival of sponges. Despite the ability of sponges to adjust to changes in the environment, only a low number of successful ex situ systems were developed (Koopmans, 2009).

Substrates and attachment are also important factors used to evaluate the growth of sponges. In case of Crambe crambe cultured in closed systems, it was found that the highest growth rate for all explants was observed in first 10 days of culture just after the cuttings were planted, as stress might have triggered regeneration process and biomass production (Belarbi et al., 2003). In case of Chondrosia reniformis also higher cellular proliferation was reported only in first 10 days compared to the latter period (Nickel and Brummer, 2003). In our study also $S$. massa exhibited good growth until first 15 days with a decreasing trend subsequently.

In our study, there were limitations in measurement of growth of sponges as methods for determination of growth of sponges like 3D-photogrammatry and underwater weighing were not used. Simple measurement was used for calculation of growth. Nutrient requirement of sponges is another interesting area of work which could be specifically taken up for sponges which might augment growth and survival. The growth and survival studies of S. massa and L. paradoxa showed that these species can be taken up for mariculture to harness their bioactive potential. In India, sponge farming is most primitive and relatively unexplored compared to other marine fauna like finfishes and shellfishes. Though sponge cultivation is one of the most challenging task when compared to other marine fauna owing to their irregular growth pattern, feeding and slow growth, they could be one of the most potential organisms for mankind since these organisms possess enormous potential for drug development.

\section{Acknowledgements}

The authors are grateful to the Director ICAR-CIARI, Port Blair and the Director, ICAR-CIFE, Mumbai for providing facilities to carry out the work.

\section{References}

Aknin, M., Gros, M., Vacelet, J., Kashman, Y. and Bialecki, A. G. 2010. Sterols from the Madagascar sponge Fascaplysinopsis sp. Mar Drugs., 8(12): 2961-2975.

Ayling, A. L. 1983. Growth and regeneration rates in thinly encrusting demospongiae from temperate waters. Biol. Bull., 165: 343-352.

Bakus, G. J. 1967. Sedimentation and benthic invertebrates of Fanning Island, Central Pacific. Mar. Geol., 6: 45-61.

Barthel, D. and Theede, H. 1986. A new method for the laboratory culture of sponges and its application to experimental studies. Ophelia, 25(2): 75-82.
Belarbi, E. H., Ramirez Dominguez, M., Ceron Garcia, M, C., Contreras Gomez, A., Garcia Camacho, F. and Molina Grima, E. 2003. Cultivation of explants of the marine sponge Crambe crambe in closed systems. Biomol. Eng. 20: 333-337.

Bergmann, W. and Feenay, R. J. 1950. The isolation of a new thymidine pentoside from sponges. J. Ame. Chem Soc., 72: 2809-2810.

Colin, P. L. and Arneson, A. C. 1995. Tropical Pacific invertebrates, $2^{\text {nd }}$ edn. Coral Reed Press, Beverly Hills, California, USA, 304 pp.

Cotte, J. 1908. Sponge culture. Bull. Bur. Fish., 28: 587-614.

Crawshay, L. R. 1939. Studies in the market sponges Growth from the planted cutting. J. Mar Biol. Ass. U.K, 23: $553-574$

Dayton, P. K. 1979. Observations of growth, dispersal and population dynamics of some sponges in McMurdo Sound, Antarctica. Colloques Internation aux du C. N. R. S., 291: 271- 282.

De Caralt, S., Anchez-Fontenla, J. S., Uriz, M. J. and Wijffels, R. H. 2010. In situ aquaculture methods for Dysideaavara (Demospongiae, Porifera) in the North-western Mediterranean. Mar. Drugs, 8(6): 1731-1742.

De Voogd, N. J. 2005. Indonesian sponges: biodiversity and mariculture potential, University of Amsterdam. ISBN- 90-9019343-X. 174 pp.

Duckworth, A. R., Battershill C. N. and Bergquist, P. R. 1997. Influence of explant procedures and environmental factors on culture success of three sponges. Aquaculture, 156: 251-267.

Duckworth, A. 2009. Farming sponges to supply bioactive metabolites and bath sponges: a review. Mar. Biotechnol., 11(6): 669-679.

Fry, W. G. 1971. The biology of larvae of Ophlitaspongia seriata from toe North Wales populations. In: Crisp, D. J. (Ed.), Proceedings of the Fourth European Marine Biology Symposium, Cambridge University Press, Cambridge, U. K., p.155-178.

Garrabou, J. and Zabala, M. 2001. Growth dynamics in four Mediterranean Demosponges. Estuar. Coast Shelf Sci., 52: 293-303.

Koopmans, M. 2009. Growth and metabolism of sponges. $\mathrm{Ph}$. D. thesis. Wageningen university, The Netherlands, ISBN: 978-90-8585-441-8.

Lipton, A. P. and Shine, S. 2009. Mariculture of marine sponges for drug development: bioactivity potentials of cultured sponges, Callyspongia subarmigera (Ridley) and Echinodictyum gorgonoides (Dendy). Mar. Fish. Inf. Serv. T\& E Ser., 202: 7-10.

Macmillan, S. M. 2002. Starting a succesfull commercial sponge aquaculture farm. University of Hawaii Sea Grant College 
Programme Communications Office, School of Ocean and Earth Science and Technology, CTSA Publication, $120 \mathrm{pp}$.

Nickel, M. and Brummer, F. 2003. In vitro sponge fragment culture of Chondrosia reniformis (Nardo, 1847). J. Biotechnol., 100: $147-159$.

Osinga, R., Belarbi, E. H., Molina Grima, E., Tramper, J. and Wijffels, R. H. 2003. Progress towards a controlled culture of the marine sponge Pseudosuberites andrewsi in a bioreactor. J. Biotechnol., 100: 141-146.

Osinga, R., Kleijn, R., Groenendijk, E., Niesink, P., Tramper, J. and Wijffels, R. H. 2001. Development of in vivo sponge cultures: particle feeding by the tropical sponge Pseudosuberites (Aff) andrewsi. Mar. Biotechnol.,3: 544-554.

Osinga, R., Tramper, J. and Wijffels, R. H. 1999. Cultivation of marine sponges. Mar. Biotechnol., 1: 509-532.

Porrier, M. A., Francis, J. C. and Labiche, R. A. 1981. A continuous flow system for growing freshwater sponges in laboratory. Hydrobiologia, 79: 255-259.

Pronzato, R. 1999. Sponge - fishing, disease and farming in the Mediterranean Sea. Aquatic Conservation: Mar. Freshw. Ecosyst., 9: 485493.

Schiefenhovel, K. and Kunzmann, A. 2012. Sponge farming trials: Survival, attachment and growth of two Indo-Pacific sponges, Neopetrosia sp. and Stylissa massa. J. Mar. Biol., doi:10.1155/2012/417360.

Simpson, T. L. 1968. The biology of the marine sponge Microciona prolifera (Ellis and Solander): temperature related annual changes in functional and reproductive elements with a decrioption of larval metamorphosis. J. Exp. Mar. Biol. Ecol., 2: 252-277.

Sipkema, D., Franssen, M. C. R., Osinga, R., Tramper, J. and Wijffels, R. H. 2005. Marine sponges as pharmacy. Mar. Biotechnol., 7: 142-162.

Smith, H. M. 1897. The Florida commercial sponges. Fish Commission Bull., 15: 225-240.

Tasdemir, D., Mallon, R., Greenstein, M., Feldberg, L. R., Kim, S. C., Collins, K., Wojciechowicz, D., Mangalindan, G. C., Concepcion, G. P., Harper, M. K. and Ireland, C. M. 2002. Aldisine alkaloids from the Philippine sponge Stylissa massa are potent inhibitors of mitogen-activated protein kinase kinase-1 (MEK-1). J. Med. Chem., 45(2): 529-532.

Van Treeck, P., Eisinger, M., Muller, J., Paster, M. and Schuhmacher, H. 2003. Mariculture trials with Mediterranean sponge species. The exploitation of an old natural resource with sustainable and novel methods. Aquaculture, 218: 439-455.

Verdenal, B. and Vacelet, J. 1990. Sponge culture on vertical ropes in the North-western Mediterranean Sea. In: Rutzler, K. (Ed.), New perspectives in sponge biology. Smithsonian Institution Press, Washington DC, p. 416-424.

Vinod, K., Goerge, M. and Manisseri, M. K. 2009. Preliminary studies on the growth in captivity of Spirastrella inconstans (Dendy) collected from the Intertidal region of Palk Bay, South-east of India. Mar. Fish. Inf. Serv.T\&E Ser., 202: 4-6.

Waburton, F. E. 1958. Reproduction of fused larvae in the boring sponge, Cliona celata Grant. Nature, 181: 493-494.

Date of Receipt ～: 29.09.2014

Date of Acceptance : 13.10 .2016 